\title{
Identifying the Most Potent Dual-Targeting Compound(s) against 3CLprotease and NSP15exonuclease of SARS-CoV-2 from Nigella sativa: Virtual Screening via Physicochemical Properties, Docking and Dynamic Simulation Analysis
}

Syed Mohd Danish Rizvi ${ }^{1}\left(\mathbb{D}\right.$, Talib Hussain ${ }^{2, *}$, Afrasim Moin ${ }^{1, *(\mathbb{D})}$, Sheshagiri R. Dixit ${ }^{3} \mathbb{D}$, Subhankar P. Mandal $^{3}$, Mohd Adnan ${ }^{4}\left(\mathbb{D}\right.$, Qazi Mohammad Sajid Jamal ${ }^{5}$, Dinesh C. Sharma ${ }^{6,7}$ (D), Abulrahman Sattam Alanazi ${ }^{8}$ and Rahamat Unissa ${ }^{1}$

check for

Citation: Rizvi, S.M.D.; Hussain, T.; Moin, A.; Dixit, S.R.; Mandal, S.P.; Adnan, M.; Jamal, Q.M.S.; Sharma, D.C.; Alanazi, A.S.; Unissa, R. Identifying the Most Potent Dual-Targeting Compound(s) against 3CLprotease and NSP15exonuclease of SARS-CoV-2 from Nigella sativa: Virtual Screening via Physicochemical Properties, Docking and Dynamic Simulation Analysis. Processes 2021, 9 , 1814. https://doi.org/10.3390/ pr9101814

Academic Editor: Teodorico De Castro Ramalho

Received: 2 September 2021 Accepted: 9 October 2021 Published: 13 October 2021

Publisher's Note: MDPI stays neutral with regard to jurisdictional claims in published maps and institutional affiliations.

Copyright: (c) 2021 by the authors. Licensee MDPI, Basel, Switzerland. This article is an open access article distributed under the terms and conditions of the Creative Commons Attribution (CC BY) license (https:/ / creativecommons.org/licenses/by/ $4.0 /)$.
1 Department of Pharmaceutics, College of Pharmacy, University of Hail, Hail P.O. Box 2440, Saudi Arabia; syedrizvi10@yahoo.com (S.M.D.R.); srunissa@gmail.com (R.U.)

2 Department of Pharmacology and Toxicology, College of Pharmacy, University of Hail, Hail P.O. Box 2440, Saudi Arabia

3 Department of Pharmaceutical Chemistry, J.S.S College of Pharmacy, J.S.S Academy of Higher Education \& Research, Mysore 570004, Karnataka, India; sheshagiridixit@jssuni.edu.in (S.R.D.); subhankar293@gmail.com (S.P.M.)

4 Department of Biology, College of Science, University of Hail, Hail P.O. Box 2440, Saudi Arabia; drmohdadnan@gmail.com

5 Department of Health Informatics, College of Public Health and Health Informatics, Qassim University, Al Bukayriyah 52571, Saudi Arabia; m.quazi@qu.edu.sa

6 School of Life Sciences, The Glocal University, Saharanpur 247121, Uttar Pradesh, India; ddcsharma@gmail.com

7 Department of Microbiology, School of Life Sciences, Starex University, Gurugram 122413, Haryana, India

8 Department of Clinical Pharmacy, College of Pharmacy, University of Hail, Hail P.O. Box 2440, Saudi Arabia; aas2@hotmail.com

* Correspondence: mdth_ah@yahoo.com (T.H.); afrasimmoin@yahoo.co.in (A.M.)

Abstract: Background: The outbreak of the coronavirus (SARS-CoV-2) has drastically affected the human population and caused enormous economic deprivation. It belongs to the $\beta$-coronavirus family and causes various problems such as acute respiratory distress syndrome and has resulted in a global pandemic. Though various medications have been under trial for combating COVID-19, specific medicine for treating COVID-19 is unavailable. Thus, the current situation urgently requires effective treatment modalities. Nigella sativa, a natural herb with reported antiviral activity and various pharmacological properties, has been selected in the present study to identify a therapeutic possibility for treating COVID-19. Methods: The present work aimed to virtually screen the bioactive compounds of $N$. sativa based on the physicochemical properties and docking approach against two SARS-CoV-2 enzymes responsible for crucial functions: 3CLpro (Main protease) and NSP15 (Nonstructural protein 15 or exonuclease). However, simulation trajectory analyses for $100 \mathrm{~ns}$ were accomplished by using the YASARA STRUCTURE tool based on the AMBER14 force field with 400 snapshots every 250 ps. RMSD and RMSF plots were successfully obtained for each target. Results: The results of molecular docking have shown higher binding energy of dithymoquinone (DTQ), a compound of N. sativa against 3CLpro and Nsp15, i.e., $-8.56 \mathrm{kcal} / \mathrm{mol}$ and $-8.31 \mathrm{kcal} / \mathrm{mol}$, respectively. Further, the dynamic simulation has shown good stability of DTQ against both the targeted enzymes. In addition, physicochemical evaluation and toxicity assessment also revealed that DTQ obeyed the Lipinski rule and did not have any toxic side effects. Importantly, DTQ was much better in every aspect among the $13 \mathrm{~N}$. sativa compounds and 2 control compounds tested. Conclusions: The results predicted that DTQ is a potent therapeutic molecule that could dual-target both 3CLpro and NSP15 for anti-COVID therapy.

Keywords: SARS-CoV-2; dithymoquinone; dynamic simulation; virtual screening; physicochemical properties 


\section{Introduction}

Since the beginning of the 21st century, different coronavirus strains have been identified which cause severe pneumonia among humans [1]. COVID-19 is the name specified for an infectious disease instigated by SARS-CoV-2 (2019 novel coronavirus). Moreover, it originated in Wuhan City, China then it metastasized into a global outbreak. This is the first time, post-World War II, that such economic and social distress has been experienced. Altogether, these circumstances compelled the World Health Organization (WHO) to pronounce COVID-19 as a global pandemic [2]. Until now, nearly 198 million COVID-19 cases, alongside 4,224,466 COVID-19 deaths, have been accounted for, and this contagion proliferation is yet undefeatable with no respite in its annihilation trajectory. A significant clinical characteristic of COVID-19 and the primary cause of death in COVID-19 patients is severe acute respiratory distress syndrome (ARDS) [3,4]. As per WHO, it is still a serious issue affecting public health [5].

MERS-CoV and SARS-CoV belong to the $\beta$-coronavirus family following 229E, NL63, OC43, HKU1 viruses; SARS-CoV-2 is the seventh known coronavirus. SARS-CoV-2 has an RNA (+) encapsulated inside the lipid membrane. It has a viral genome that is identical to the SARS-CoV, MERS, bat-CoV RatG13 genome, and the bat is considered the natural host of the virus [6-8]. The whole genome of the SARS-CoV-2 can be categorized to ORF's (open reading frames) at the $3^{\prime}$ end of the genome, coding the structural and accessory proteins. The structural proteins include the Envelope (E), spike glycoprotein (S), membrane (M), and nucleocapsid $(\mathrm{N})$ proteins $[9,10]$. There are 16 nonstructural proteins (NSP1-NSP16) in the number encoding for enzymes of vital functions such as replication and transcription, including main protease (3CLpro), RNA-dependent RNA polymerase (RdRP), helicase, Exo, and endonucleases (NSP15) which account for the highly conserved regions for targeting the coronavirus [11,12].

Wide varieties of bioactive molecules are available in natural products with potent antiviral efficacy, among which Nigella sativa is envisaged to have antiviral efficacy against coronavirus infection. It was reported to have antiviral efficacy $[13,14]$. It was also shown to have anti-inflammatory, immunomodulating, and antimicrobial properties $[15,16]$. N. sativa has potent antiviral activity against HIV-1 replication, herpes simplex and Hepatitis B virus [17], Hepatitis C Virus [18], and influenza virus H5N1 [19] in vitro. The reported antiviral efficacy and medical importance of $N$. sativa make it a potential therapeutic candidate against SARS-CoV-2.

The volatile oils of $N$. sativa are linked with its biological activities, which consist of trans-anethole, $\alpha$-pinene, $\beta$-pinene, carvacrol, carvone, $\mathrm{p}$-cymene, dithymoquinone, limonene, longifolene, $\alpha$-thujene, thymohydroquinone, thymol, and thymoquinone as major active compounds [20-23]. All these compounds have been reported to have antiviral potential. Trans-anethole has been reported to repress the infectivity of the herpes virus by $90 \%$ with a high selectivity index of 160 [24]. The $\alpha$ - and $\beta$-pinene compounds showed potency against the infectious bronchitis virus via interacting with its nucleocapsid protein [25]. Carvacrol showed marked antiviral activity against the herpes simplex virus 2 by the intracellular RIP3-arbitrated programmed cell necrosis pathway [26], while carvone has shown an immunostimulatory response in adenovirus infected mouse models [27]. A significant (>than $80 \%$ ) reduction in plaque formation was observed when p-cymene was incubated with the herpes simplex virus 1 [28]. Similarly, longifolene, $\alpha$-thujene, and thymohydroquinone also showed antiviral potential against polyomavirus, herpesvirus, and zikavirus, respectively [29-31]. Thymol and related monoterpenes were also reported to have potential against the herpes simplex virus 1 [32]. However, thymoquinone is considered the most abundant and major compound present in the volatile oil of N. sativa, among all other compounds. Indeed, thymoquinone is known to activate several immunological responses and has shown potent antiviral activity against different viruses such as the Epstein-Barr virus, cytomegalovirus, human immunodeficiency virus, and murine 
hepatitis $C$ virus [33]. In addition, thymoquinone is present in its dimeric form as well, which is commonly known as dithymoquinone or nigellone. Dithymoquinone has shown progressive effects on humans during renal-hepatic toxicity, diabetes, and cancer [34-36].

All these findings prompted us to explore a potential lead from these 13 active compounds of N. sativa through a molecular docking and simulation approach against 3CLpro and NSP15 as a new hope for predicting effective therapeutics for COVID-19 treatment. However, in vitro and in vivo studies are warranted to validate the findings of the present study.

\section{Materials and Methods}

\subsection{Compounds and Protein Structure Retrieval}

The 3-dimensional structure of 3CLpro (ID: 6lu7) [37] and Nsp15 (ID: 6vww) [38] were retrieved from the Protein Data Bank database. The three-dimensional structure of transanethole (ID: 637563), $\alpha$-pinene (ID: 6654), $\beta$-pinene (ID: 10290825), carvacrol (ID: 10364), carvone (ID: 7439), p-cymene (ID: 7463), dithymoquinone (ID: 398941), limonene (ID: 22311), longifolene (ID: 289151), $\alpha$-thujene (ID: 17868), thymohydroquinone (ID: 95779), thymol (ID: 6989), thymoquinone (ID: 10281), lopinavir(ID: 92727), and benzopurpurin B (ID: 13816) were retrieved from the PubChem database.

\subsection{Calculation of Physicochemical Properties and Prediction of Toxicity Potential}

The individual phytochemical constituent of N. sativa was assessed for its toxicity and the physicochemical properties using the Osiris DataWarrior property explorer tool ( www.openmolecules.org, accessed on 2 September 2021) [39]. The tool was used to assess the molecular weight, the number of hydrogen bond donors and acceptors, rotatable bonds, and cLogP value. The molecular properties described by these five parameters were used to evaluate the violation of Lipinski's rule [40], which is used to predict the compound pharmacokinetics in the human body and compound suitability for oral formulations. However, the rule is used for proper drug candidate selection and not to predict the pharmacological activity of the compound. Here, $\operatorname{cLogP}$ (the logarithm of partition coefficient between n-octanol and water) was calculated for the prediction of hydrophilicity. The lower the cLogP value, the more the compound will be hydrophilic and with better absorption. In the Osiris DataWarrior tool's analysis, the predicted toxicity values were dependent on the comparison of the precalculated investigated molecules with the structures of the tested molecules. Various aspects and effects of the toxicity, including tumorigenicity, mutagenicity, and irritability of the tested compounds, were also studied using the Osiris DataWarrior tool.

\subsection{Molecular Docking}

The molecular docking study was carried out as per the protocol followed by Rizvi et al. [41]. After the addition of gasteiger partial charges to the proteins, the MMFF94 force field was applied for the energy minimization of each compound. The rotatable bonds were defined following the inclusion of non-polar hydrogen atoms. Then the solvation parameters were added with Kollman united atom type charges and hydrogen atoms. The grids were created using the auto grid in the dimension $60 \times 60 \times 60 \AA$ with the spatial distance between the points of approximately $0.375 \AA$. For specific targeting, the $X, Y$, and $\mathrm{Z}$ coordinates were fed as $-16.539,15.246$, and 67.334 for 3CLpro and $-72.419,24.902$, and -37.184 for Nsp 15, respectively. To calculate the electrostatic terms and Van der Waals forces, they were maintained with default parameters and dielectric functions in AutoDock. The molecular docking simulation was conducted using the 'Solis and Wets local search method' and 'Lamarckian genetic algorithm', where other parameters including torsion, orientation, and initial positions were arbitrarily set. Furthermore, 100 different runs were set, which ended after 2,500,000 evaluations for each experiment. The size of the population for the study was 150 . 


\subsection{LIGPLOT+ Analysis}

The best-docked conformation was chosen and analyzed using LIGPLOT+ Version v.2.1 [42]. The hydrophobic and hydrogen bond interactions were examined and the LIGPLOT algorithm was applied to convert 3D into 2D final figures.

\subsection{Molecular Dynamics Simulation Study}

The docking complexes of 3CLpro and Nsp15 bounded with dithymoquinone (DTQ) (the ligand identified and selected by screening) were subjected to molecular dynamics simulation analysis using YASARA STRUCTURE v.20.12.24.W.64 [43]. The AMBER14 force field was used to set the simulation cell boundary to periodic. The simulation cell was permitted to contain $20 \AA$ surrounding the protein and filled with solvent (water) at a density of $0.997 \mathrm{~g} / \mathrm{mL}$. To enhance the stability of the solute, the $\mathrm{H}$ bonding network was optimized [44], followed by fine-tuning the target protein protonated state via $\mathrm{pKa}$ prediction at $7.4 \mathrm{pH}$. However, to neutralize the environment, $\mathrm{NaCl}$ ions were also added to the system. At first, the energy of the system was minimized in the YASARA structure tool to rectify the covalent geometry and bumps. Here, simulated annealing and steepest descent minimization techniques were applied to eliminate clashes before running the simulation trajectory for 100ns by the 'AMBER14 force field' for the solute [45], 'TIP3P' for water, and 'AM1BCC [46] and GAFF2 [47]' for DTQ. 'Van der Waals forces' were applied with an 8 A cut-off, while 'electrostatic forces and the Particle Mesh Ewald algorithm' were applied without any cut-off limit. Using NPT ensembles [48], the systems were equilibrated by applying position restrains. Equilibration for both the complexes was integrated with a multiple time step of $2.5 \mathrm{fs}$ and $5.0 \mathrm{fs}$ for bonded and non-bonded interactions, respectively, at 1 bar pressure and a temperature of $298 \mathrm{~K}$. NPT ensembles of isobaric and isothermal conditions were maintained for the entire simulation process. The temperature control rescaling approach was used to initiate a Berendsen thermostat [49], which is based on the time-averaged temperature. Berendsen barostat [49], based on time average pressure, was used to control pressure. However, the tuned version of LINCS [50] via the multiple time-step algorithm [48] was used to constrain bonds and angles involving hydrogen. It is noteworthy to mention that the easy interphase provided by the macros tool in the YASARA structure, i.e., 'md_runfast.mcr' was used to run the total simulation process in the present study. In addition, 'md_analyze.mcr' was used to analyze the trajectory path of the simulation process. Two separate simulations were performed for 'DTQ-3CLpro' and 'DTQ-Nsp15', respectively. Figures for each simulation were generated by using the YASARA structure tool where 400 snapshots were taken each $250 \mathrm{ps}$. A ray-traced diagram of each simulation system with a cubic shape box was also generated via the YASARA structure tool (Figures S1 and S2).

\section{Results}

\subsection{Virtual Screening}

Initially, fifteen compounds including thirteen active components of $N$. sativa and two controls (lopinavir and benzopurpurin B) were subjected to virtual screening via molecular docking, physicochemical and toxicity properties analysis, followed by the simulation of the selected lead compound (Figure 1). 


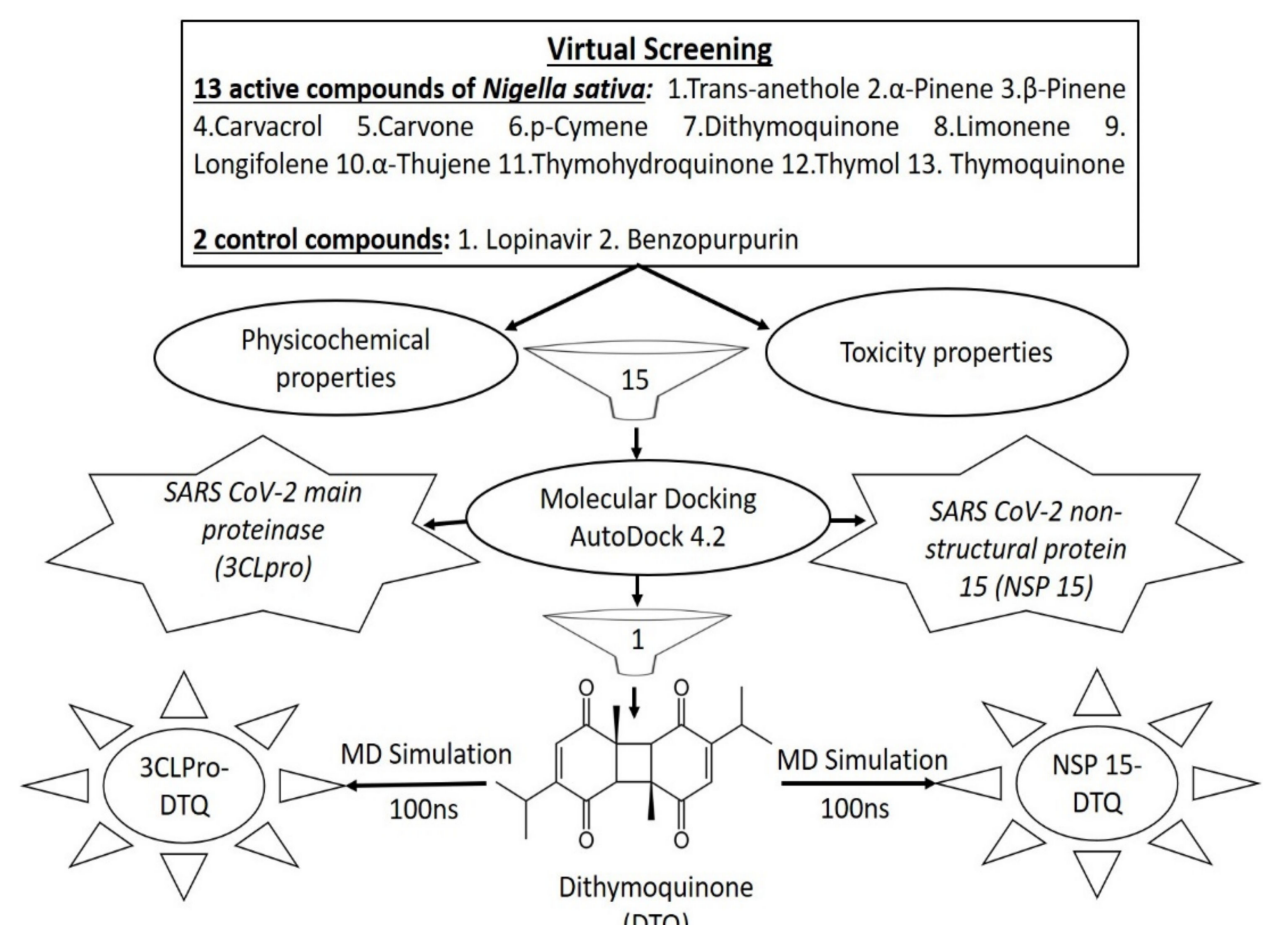

(DTQ)

Figure 1. Virtual screening of Nigella sativa compounds to select the best dual-targeting compound against the SARS-CoV-2 virus.

\subsubsection{Virtual Screening via Molecular Docking Analysis}

Active components of the N. sativa were subjected to molecular docking using Auto dock 4.2. Fifteen compounds, including the thirteen active components of N. sativa and two controls (lopinavir and benzopurpurin B), were subjected to docking analysis with the 'SARS CoV-2 main proteinase (3CLpro)' and 'SARS CoV-2 non-structural protein 15 (NSP15)' generating thirty combinations of binding. Based on the Binding Energy $(\Delta \mathrm{G})$ and Inhibition Constant (Ki), dithymoquinone (DTQ) showed a binding energy score of approximately $-8.56 \mathrm{kcal} / \mathrm{mol}$ and $-8.31 \mathrm{kcal} / \mathrm{mol}$ against $3 C L$ pro and Nsp 15 , respectively. DTQ has shown an excellent binding affinity toward both the enzymes compared to all the other compounds; whereas, the standard lopinavir exhibited a binding affinity of $-7.95 \mathrm{kcal} / \mathrm{mol}$ against 3CLpro main protease and benzopurpurin B showed a binding affinity of approximately $-5.87 \mathrm{kcal} / \mathrm{mol}$ against Nsp15. Table 1 shows the binding energy scores for ligands' molecular docking against the viral enzyme proteins 3CLpro and Nsp15.

As per the results, DTQ has been selected as the molecule of interest for effectively combating the SARS-CoV-2. The LigPlot analysis of 'DTQ-3CLPro' interaction in Figure 2a shows DTQ formed hydrogen at the Glu 166 from the O1 molecule and has a bond length of approximately $3.15 \AA$. Figure $2 \mathrm{~b}$ shows the 2D binding scheme of the DTQ and Nsp15 interaction, in which two hydrogen bonds are formed between DTQ and the active site of Nsp15 at Ile 169 and Asn200 amino acid residue with a bond length of $3.23 \AA$ and $2.61 \AA$, respectively. The hydrogen bond was formed between DTQ-Ile169 at O4 and N atoms, and DTQ-Asn200 between O3 and ND2 atoms. Overall, the results show that DTQ has a higher affinity towards the target proteins compared to all the tested compounds, confirming it as a potential multi-targeting candidate for COVID-19 treatment. 
Table 1. Molecular docking results of 'SARS CoV-2 main proteinase (3CLpro)' and 'SARS CoV-2 non-structural protein 15 (NSP15)' interaction with active components of Nigella sativa and control compounds.

\begin{tabular}{|c|c|c|c|c|}
\hline \multirow[b]{2}{*}{ Compounds } & \multicolumn{2}{|c|}{ 3Clpro } & \multicolumn{2}{|c|}{ Nsp15 } \\
\hline & $\begin{array}{c}\text { Binding Energy } \\
(\Delta \mathrm{G}) \\
\mathrm{kcal} / \mathrm{mol}\end{array}$ & $\begin{array}{l}\text { Inhibition Constant } \\
\text { (Ki) }\end{array}$ & $\begin{array}{c}\text { Binding Energy } \\
(\Delta \mathrm{G}) \\
\mathrm{kcal} / \mathrm{mol}\end{array}$ & $\begin{array}{l}\text { Inhibition Constant } \\
\text { (Ki) }\end{array}$ \\
\hline Trans-anethole & -4.92 & $246.75 \mu \mathrm{M}$ & -5.16 & $166.25 \mu \mathrm{M}$ \\
\hline$\alpha$-Pinene & -5.76 & $60.23 \mu \mathrm{M}$ & -5.36 & $118.03 \mu \mathrm{M}$ \\
\hline$\beta$-Pinene & -5.80 & $55.60 \mu \mathrm{M}$ & -5.45 & $100.81 \mu \mathrm{M}$ \\
\hline Carvacrol & -5.20 & $153.32 \mu \mathrm{M}$ & -5.50 & $92.57 \mu \mathrm{M}$ \\
\hline Carvone & -5.42 & $107.14 \mu \mathrm{M}$ & -5.55 & $85.02 \mu \mathrm{M}$ \\
\hline$p$-Cymene & -4.80 & $300.76 \mu \mathrm{M}$ & -5.19 & $157.67 \mu \mathrm{M}$ \\
\hline Dithymoquinone & -8.56 & $531.10 \mathrm{nM}$ & -8.31 & $803.86 \mathrm{nM}$ \\
\hline Limonene & -5.19 & $157.44 \mu \mathrm{M}$ & -5.28 & $134.92 \mu \mathrm{M}$ \\
\hline Longifoline & -6.48 & $17.89 \mu \mathrm{M}$ & -6.17 & $29.92 \mu \mathrm{M}$ \\
\hline$\alpha$-Thujene & -5.22 & $150.37 \mu \mathrm{M}$ & -4.97 & $226.02 \mu \mathrm{M}$ \\
\hline Thymohydroquinone & -5.35 & $120.74 \mu \mathrm{M}$ & -5.90 & $47.45 \mu \mathrm{M}$ \\
\hline Thymol & -5.19 & $157.16 \mu \mathrm{M}$ & -5.27 & $136.00 \mu \mathrm{M}$ \\
\hline Thymoquinone & -5.25 & $142.75 \mu \mathrm{M}$ & -5.66 & $71.50 \mu \mathrm{M}$ \\
\hline Lopinavir * & -7.95 & $1.48 \mu \mathrm{M}$ & - & - \\
\hline Benzopurpurin B * & - & - & -5.87 & $50.15 \mu \mathrm{M}$ \\
\hline
\end{tabular}

\footnotetext{
${ }^{*}$ Control drugs/compounds
}
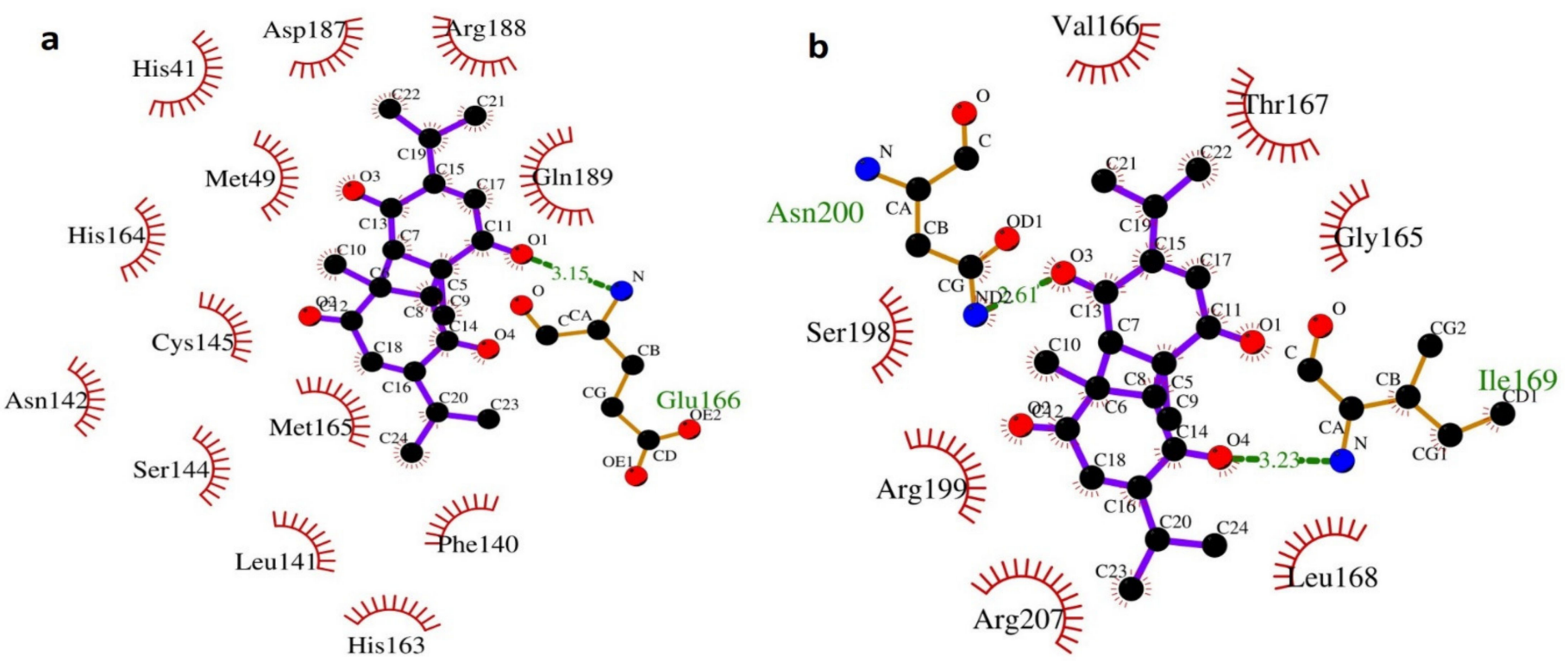

Figure 2. LigPlot 2D representation of the interaction between dithymoquinone DTQ and generating enzyme protein active sites. (a) DTQ with 3CLpro and (b) DTQ with Nsp15.

\subsubsection{Virtual Screening via Physicochemical Properties Analysis}

The physicochemical properties and toxicity potential of phytoconstituents of $N$. sativa were assessed using the Osiris DataWarrior property explorer tool for drug-likeness. The 13 phytoconstituents of $N$. sativa, including trans-anethole, $\alpha$-pinene, $\beta$-pinene, car- 
vacrol, carvone, p-cymene, dithymoquinone, limonene, longifoline, $\alpha$-thujene, thymohydroquinone, thymol, and thymoquinone have not violated the Lipinski rule as shown in Table 2. Among the control drugs, both lopinavir and benzopurpurin violated the Lipinski rule with a molecular weight of approximately $628.81 \mathrm{~g} / \mathrm{mol}$ and $680.76 \mathrm{~g} / \mathrm{mol}$ higher than $500 \mathrm{~g} / \mathrm{mol}$, respectively. Lopinavir and benzopurpurin also have a higher number of rotatable bonds and hydrogen bond receptors. Our molecule of interest, DTQ, has a molecular weight of $328.40 \mathrm{~g} / \mathrm{mol}$, which is suitable for crossing the biosystem's membrane barriers. It also has a cLogP value of approximately 2.73 , indicating the compound's moderately lipophilic nature with proper absorption in the gastro-intestinal tract with no violation of the Lipinski rule. Thus, it makes a promising candidate for combating COVID-19.

Table 2. Physicochemical properties of 'active components of Nigella sativa' and 'control compounds'.

\begin{tabular}{|c|c|c|c|c|c|c|}
\hline \multirow[b]{2}{*}{ Compounds } & \multicolumn{6}{|c|}{ Physiochemical Parameters } \\
\hline & $\begin{array}{c}\text { Molecular } \\
\text { Weight (g/mol) }\end{array}$ & $\operatorname{cLog} P * *$ & $\begin{array}{l}\text { Hydrogen } \\
\text { Bond Donors }\end{array}$ & $\begin{array}{l}\text { Hydrogen } \\
\text { Bond } \\
\text { Acceptors }\end{array}$ & $\begin{array}{c}\text { Number of } \\
\text { Rotatable } \\
\text { Bonds }\end{array}$ & $\begin{array}{l}\text { Lipinski's } \\
\text { Violation }\end{array}$ \\
\hline Rule & $<500$ & $\leq 5$ & $<5$ & $<10$ & $\leq 10$ & $\leq 1$ \\
\hline Trans-anethole & 148.20 & 2.68 & 0 & 1 & 2 & 0 \\
\hline$\alpha$-Pinene & 136.23 & 2.72 & 0 & 0 & 0 & 0 \\
\hline$\beta$-Pinene & 136.23 & 2.79 & 0 & 0 & 0 & 0 \\
\hline Carvacrol & 150.22 & 2.84 & 1 & 1 & 1 & 0 \\
\hline Carvone & 150.22 & 2.65 & 0 & 1 & 1 & 0 \\
\hline p-Cymene & 134.22 & 3.19 & 0 & 0 & 1 & 0 \\
\hline Dithymoquinone & 328.40 & 2.73 & 0 & 4 & 2 & 0 \\
\hline Limonene & 136.23 & 3.36 & 0 & 0 & 1 & 0 \\
\hline Longifoline & 204.35 & 4.06 & 0 & 0 & 0 & 0 \\
\hline$\alpha$-Thujene & 136.23 & 2.78 & 0 & 0 & 1 & 0 \\
\hline Thymohydroquinone & 166.21 & 2.49 & 2 & 2 & 1 & 0 \\
\hline Thymol & 150.22 & 2.84 & 1 & 1 & 1 & 0 \\
\hline Thymoquinone & 164.20 & 1.63 & 0 & 2 & 1 & 0 \\
\hline Lopinavir * & 628.81 & 4.84 & 4 & 9 & 15 & 2 \\
\hline Benzopurpurin B * & 680.76 & 4.98 & 4 & 12 & 7 & 2 \\
\hline
\end{tabular}

\subsubsection{Virtual Screening via Toxicity Assessment}

The toxicity assessment of the phytoconstituents was carried out using the Osiris DataWarrior property explorer tool. Of thirteen compounds, three compounds, including $\beta$ pinene, dithymoquinone, and longifoline, had toxic effects such as mutagenic, tumorigenic, and reproductive irritant effects (Table 3). Toxicity analysis showed that DTQ remained inactive for the predictive toxicity parameters used and was expected to be non-toxic.

\subsection{Molecular Dynamic Simulation Study}

Based on virtual screening, dithymoquinone (DTQ) was selected for dynamic simulation analysis. Molecular dynamic (MD) simulation studies were performed on the YASARA structure tool v.20.12.24.W.64 (using AMBER14 force field) to understand the protein-ligand complex's dynamic activity in a solvent environment over a period of time. Simulated conditions were optimized to map the stabilization of the 'DTQ-3CLpro' and 'DTQ-NP15' complexes and all the parameters were maintained throughout the simulation time. Simulations were performed three times for a time period of 100ns with the naïve protein alone and with the ligand-protein complex. Understanding the binding affinity 
and the protein-ligand complex's stability in a time-bound environment was the ultimate aim for performing the dynamic studies.

Table 3. Toxicity potential of 'active components of Nigella sativa' and 'control compounds'.

\begin{tabular}{ccccc}
\hline \multirow{2}{*}{ Compounds } & \multicolumn{4}{c}{ Toxicity Risks } \\
\cline { 2 - 5 } Trans-anethole & Mutagenic & Tumorigenic & Reproductive Effect & Irritant \\
\hline$\alpha$-Pinene & High & High & High & None \\
\hline$\beta$-Pinene & None & None & None & High \\
\hline Carvacrol & None & None & None & None \\
\hline Carvone & None & None & None & High \\
\hline$p$-Cymene & None & Low & None & Low \\
\hline Dithymoquinone & None & None & None & High \\
\hline Limonene & None & None & None & None \\
\hline Longifoline & None & None & None & None \\
\hline$\alpha$-Thujene & None & None & None & Low \\
\hline Thymohydroquinone & High & Low & None & None \\
\hline Thymol & High & None & High & None \\
\hline Thymoquinone & High & None & None & None \\
\hline Lopinavir * & None & None & None & High \\
\hline Benzopurpurin B ${ }^{*}$ & High & High & High & High \\
\hline * Control drugs/compounds & & &
\end{tabular}

*Control drugs/compounds.

The AMBER14 force field was employed to generate a plot for the total potential energy of the system (Figure 3). Once the simulation is initiated from a ground zero or frozen energy-minimized confirmation, a steep energy rise is typically observed through the initial picoseconds of the simulation run. This rise in energy is due to partial storage of kinetic energy as potential energy and, importantly, the potential energy usually does not decrease during a large time-scale due to counter ions. They are positioned primarily with lower potential energy near the charged solute groups. From here, they will separate to increase potential energy and entropy. It can be observed from the plot (Figure 3a) that the potential energy of the system for the DTQ-3CLpro complex fluctuated from $-1,223,500 \mathrm{~kJ} / \mathrm{mol}$ to $-1,218,500 \mathrm{~kJ} / \mathrm{mol}$. While, for the DTQ-NSP15 complex (Figure $3 \mathrm{~b}$ ), the total potential energy of the system fluctuated from $-1,219,000 \mathrm{~kJ} / \mathrm{mol}$ to $-1,213,000 \mathrm{~kJ} / \mathrm{mol}$. Importantly, fluctuations in both the systems were within an acceptable range demonstrating the stability and validity of the simulation.

The solute root mean square deviation (RMSD) for the starting structure was plotted for both the 'DTQ-3CLpro' and 'DTQ-NSP15' complexes (Figure 4). It shows three RMSDs, i.e., RMSD for Calpha (Ca), RMSD for backbone (Bb), and RMSD for all heavy atoms (All) for each complex. The RMSD results (Figure 4a) for the DTQ-3CLpro complex showed that RMSD Ca and RMSDBb plots have slight fluctuations until 20 ns; although, from 20 ns to $100 \mathrm{~ns}$ both the plots were overlaying with minimal fluctuations. However, backbone RMSD fluctuations for the 'DTQ-3CLpro' complex were within the range of between 1 and $2.8 \AA$. 

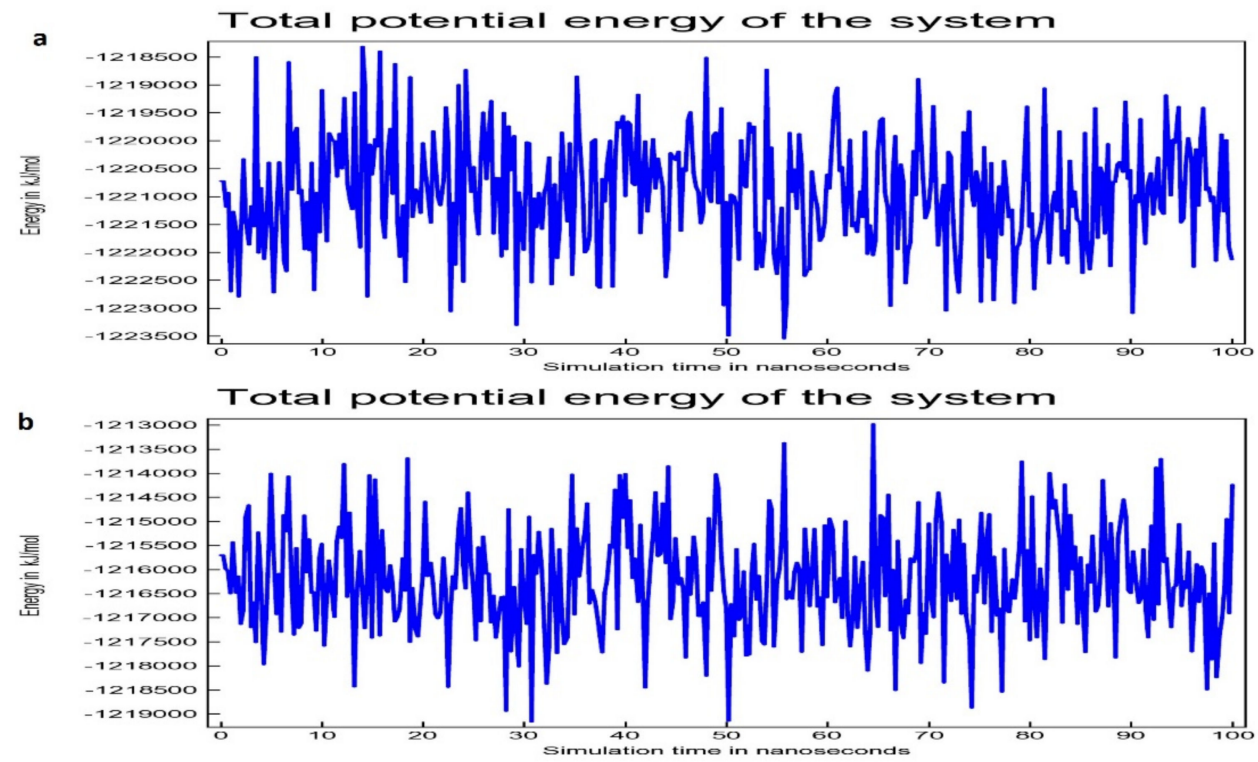

Figure 3. Plot of total potential energy of the system for (a) DTQ-3CLpro complex (b) DTQ-NSP15 complex versus simulation time of $100 \mathrm{~ns}$.
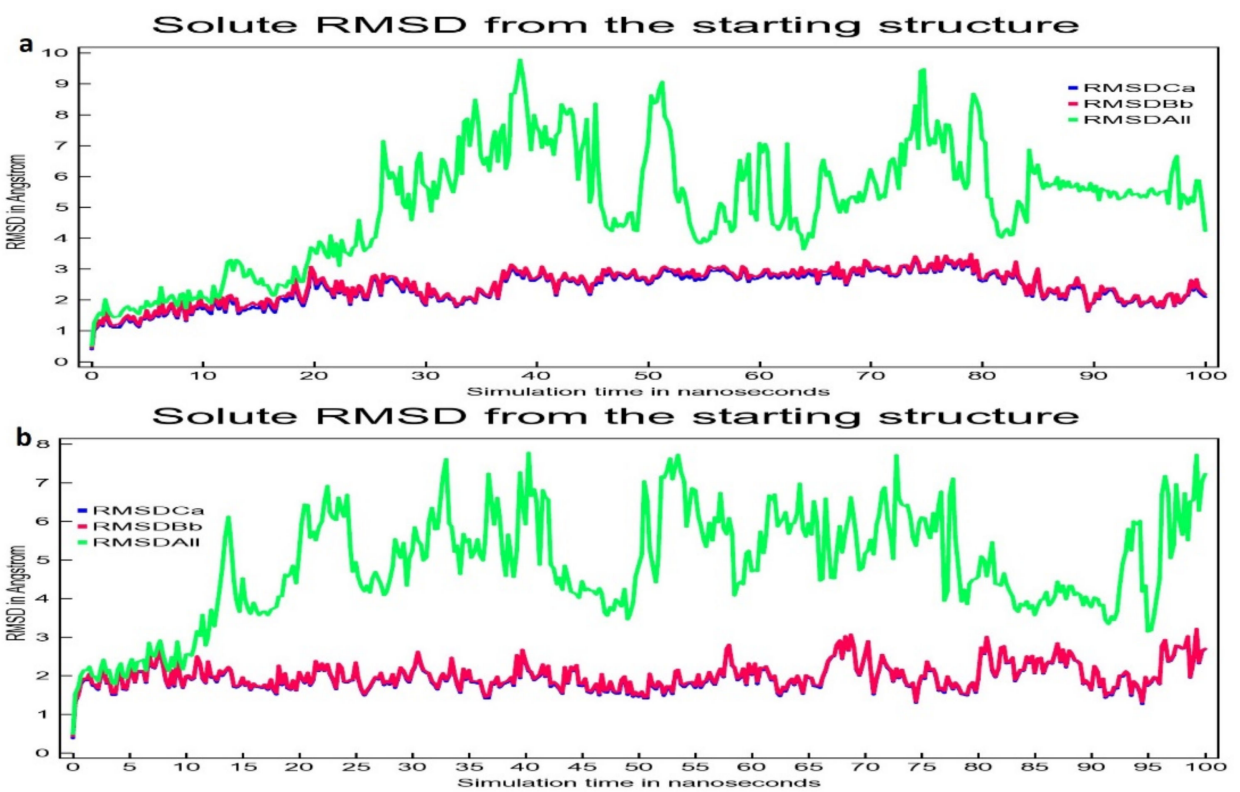

Figure 4. Solute root mean square deviation (RMSD) for (a) DTQ-3CLpro complex (b) DTQ-NSP15 complex versus simulation time of $100 \mathrm{~ns}$.

On the other hand, the RMSD results (Figure 4b) of the 'DTQ-NSP15' complex showed the overlapping of the RMSDCa and RMSDBb plots from the beginning of the simulation until 100 ns. After 65 ns, little fluctuation was observed, while the overall range of backbone RMSD fluctuations was acceptable, i.e., 1.5-2.8 ̊. For the 'DTQ-3CLpro' and 'DTQ-NSP15' complexes, RMSD for heavy atoms showed fluctuations between $20 \mathrm{~ns}$ and $12 \mathrm{~ns}$ within the limit of $9 \AA$ and $8 \AA$, respectively. Backbone RMSD results depicted that the 'DTQ-3CLpro' complex would reach equilibrium after $35 \mathrm{~ns}$ time, whereas the 'DTQ-NSP15' complex would reach equilibrium after $5 \mathrm{~ns}$ time (with little fluctuations after $65 \mathrm{~ns}$ ), reflecting structural protein flexibility being reserved in their respective complex form.

Residual-wise fluctuations could be seen from the root mean square fluctuation (RMSF) plot (Figure 5), where RMSF / solute residue was evaluated from the (avg.) RMSF of each 
atom was included in the residue. The RMSF for the DTQ-3CLpro complex (Figure 5a) and DTQ-NSP15 complex (Figure 5b) were found to be $5.18 \AA$ and $3.98 \AA$, respectively.

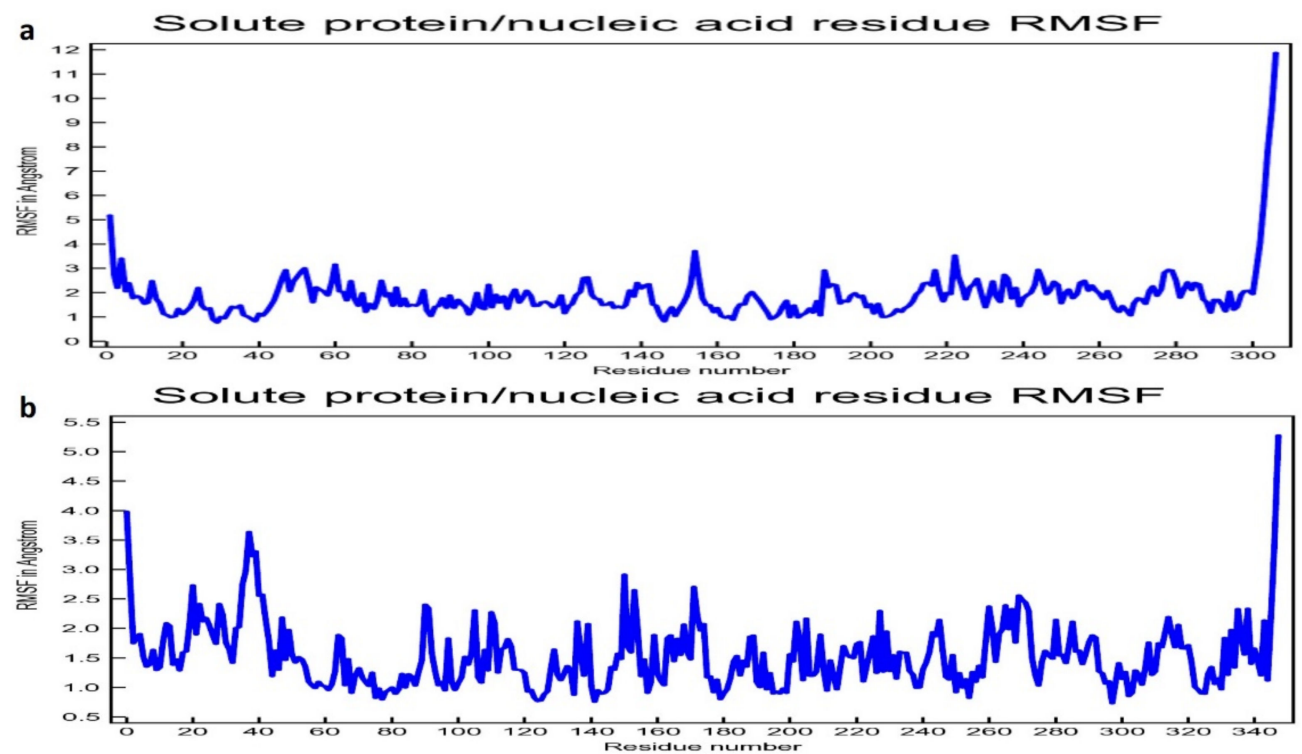

Figure 5. Root mean square fluctuation (RMSF) per solute protein residue for (a) DTQ-3CLpro complex (b) DTQ-NSP15 complex.

The radius of gyration for both the simulated protein complexes was plotted in Figure 6. The calculation for the radius of gyration is dependent on the center of mass of the protein that indicates the compactness of the protein structure. It will remain steady if the protein shows stability; however, due to instability, it will change with time. Importantly, in our study, both 3CLpro (Figure 6a) and Nsp15 (Figure 6b) showed little fluctuation that corresponded to their stability with time. Fluctuations for 3CLpro and Nsp15 were in an acceptable range between $1.6 \AA$ and $1.4 \AA$, respectively.

Stability and successful protein folding were also analyzed by the number of hydrogen bonds. The hydrogen bond analysis showed a growing number of bonds with respect to time during the entire $100 \mathrm{~ns}$ simulation for both simulations (Figure 7). It was apparent that, although the number of hydrogen bonds fluctuated during simulation, the stable nature of the protein did not change.

In addition, the dynamic cross-correlation matrix for both complexes was also obtained from the simulation analysis (data not shown for concision). However, some of the snapshots from the simulation process for the DTQ-3CLpro complex and DTQ-NSP15 complex are shown in Figures 8 and 9, respectively. Conclusively, all the simulation data suggested that both complexes were stable after initial fluctuations; however, DTQ-NSP 15 showed more stability than the DTQ-3CLPro complex. 

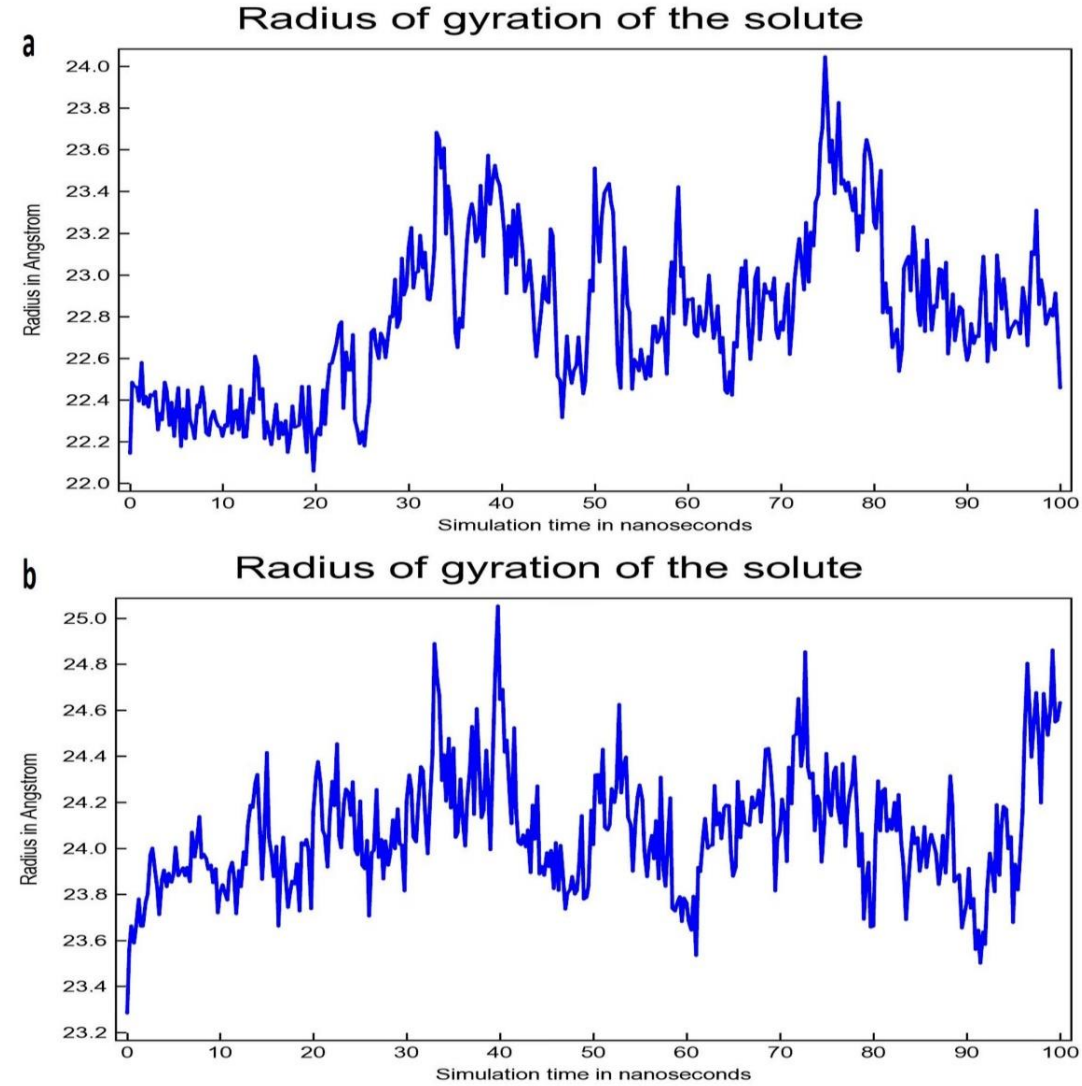

Figure 6. Radius of gyration of the solute protein for (a) DTQ-3CLpro complex (b) DTQ-NSP15 with respect to the simulation time of $100 \mathrm{~ns}$.
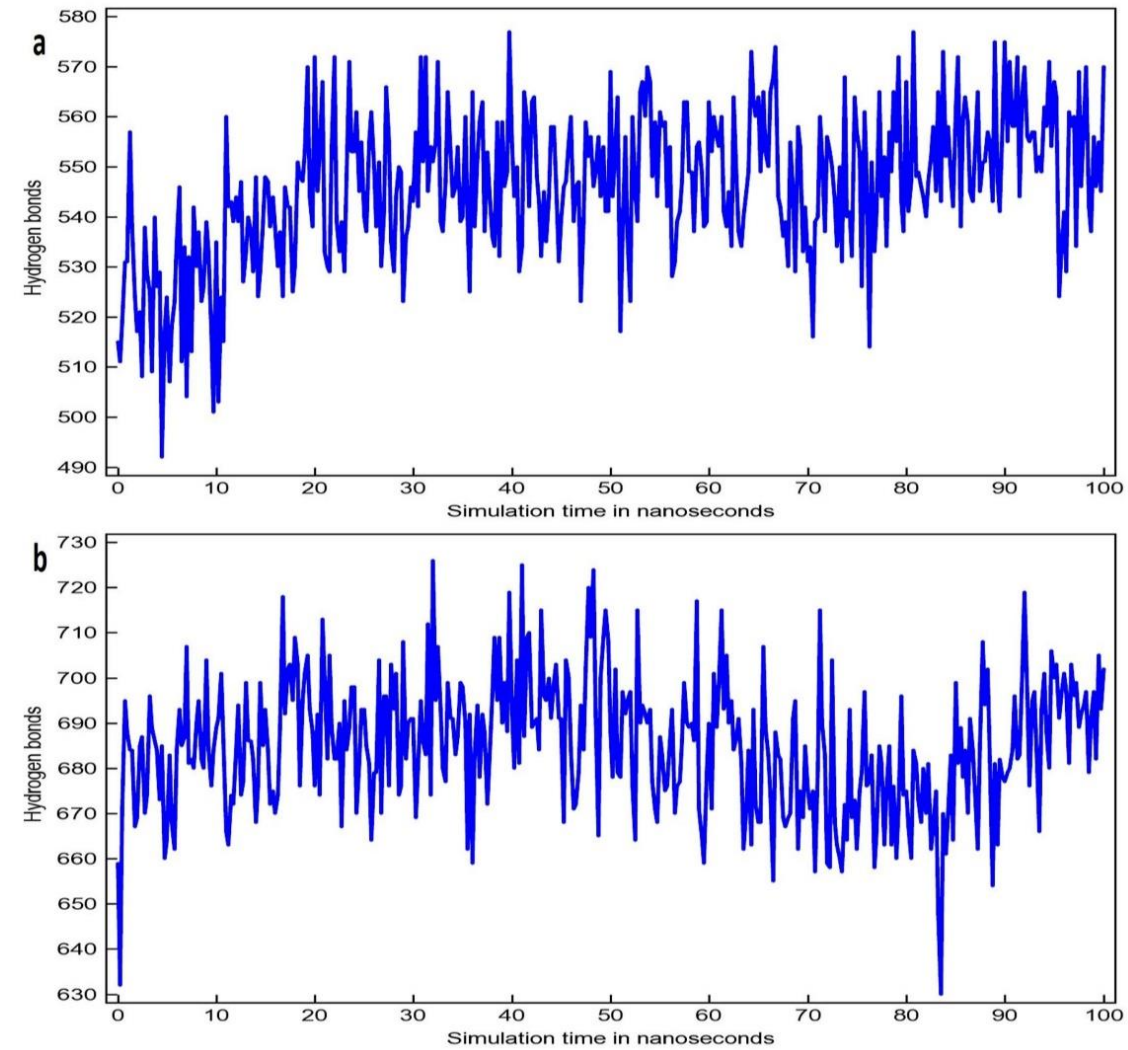

Figure 7. Number of hydrogen bonds for (a) DTQ-3CLpro complex and (b) DTQ-NSP15 with respect to the simulation time of $100 \mathrm{~ns}$. 


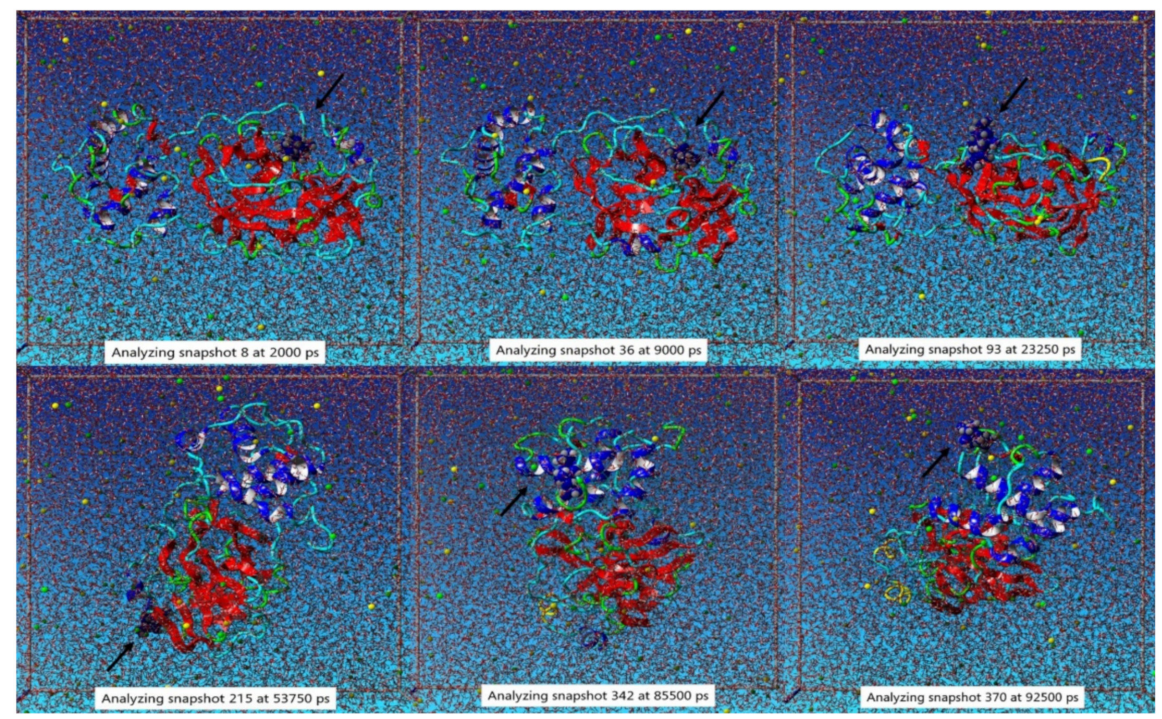

Figure 8. Snapshots of molecular dynamic simulation process of DTQ-3CLpro complex.

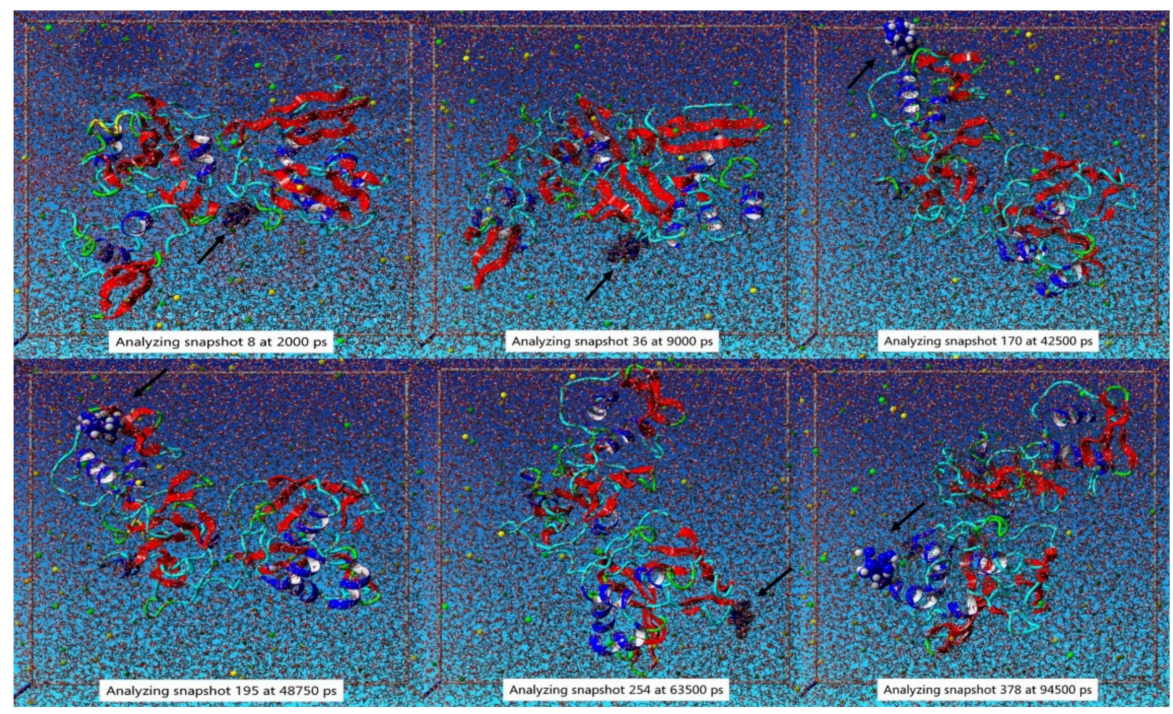

Figure 9. Snapshots of the molecular dynamic simulation process of the DTQ-NSP15 complex.

\section{Discussion}

The outbreak of COVID-19 in Wuhan, China's Hubei province, opens up new perspectives for discovering synthetic and natural small compounds to find leads that could be used to develop feasible antiretroviral medications. The sequenced 3D-crystallographic structures of 3CLpro and NSP15 enzyme proteins of SARS-CoV-2 were available from the PDB database [37,38].

The 3CLpro has been responsible for regulating protease activity in the virus, making it a therapeutic target for COVID-19. The protease activity was attributed to the Cys-His catalytic active site, which subsequently leads to the inhibition of the protease activity responsible for replicating the virus [51]. The secondary structure of the 3CLpro protein consists of three domains where the antiparallel $\beta$-barrel can be observed in Domains I and II; whereas, in domain III, the antiparallel globular cluster was connected via long loop to Domain II $[52,53]$. Recently NSP15 has been identified as a therapeutic target for COVID-19 treatment as they are essential for their life cycle and virulence. Each unit of NSP15 is composed of approximately 345 amino acids, which are folded into three domains. They are crucial for virus replicase and transcriptase formation. NSP15 tends to suppress the innate immunity (type I IFN (IFN- $\alpha / \beta)$ ) via infecting macrophages and causing the 
evasion of the virus from the immune system $[54,55]$ that makes it a susceptible target for COVID-19 therapeutics. The work aimed to identify the potential therapeutic lead from the $N$. sativa phytoconstituents due to its previously reported pharmacological properties for antiviral treatment. The phytoconstituents were screened by physicochemical properties and molecular docking, followed by dynamics simulation against the therapeutic targets, i.e., 3CLpro and NSP15.

A carbonyl polymer of thymoquinone, dithymoquinone (DTQ), was a more promising compound against the selected targets. The results clearly showed that the DTQ had exerted higher binding affinity towards the two target proteins with a binding energy of $-8.56 \mathrm{kcal} / \mathrm{mol}$ and $-8.31 \mathrm{kcal} / \mathrm{mol}$ against 3CLpro and Nsp15, respectively. The binding energy of all phytoconstituents against target proteins is shown in Table 1 . The physicochemical properties were assessed using the Osiris DataWarrior property explorer tool. Results from Tables 2 and 3 show that DTQ does not have any toxic effects and obeys the Lipinski rule, which makes it a safe therapeutic candidate. Its partial water solubility character makes it suitable for oral administration. Importantly, DTQ was better than the positive control Lopinavir (3CLpro) and benzopurpurin B (Nsp15) in every aspect. Molecular dynamic simulation for $100 \mathrm{~ns}$ with target proteins in their naïve and ligand complex form revealed good stability of DTQ — target proteins that are evident from the RMSD and hydrogen bond formation. Additionally, DTQ has shown that it can target both proteins (3CLpro and Nsp15) with almost equal efficacy, which is predicted to increase its antiviral efficacy against SARS-CoV-2.

\section{Conclusions}

The results predict that dithymoquinone (DTQ) has good affinity and stability against the target proteins 3CLpro and NSP15. It can exert its antiviral effect by inhibiting the virus's vital functions such as replication, protease activity, and life cycle. DTQ might be used as a potential therapeutic molecule against COVID-19. However, further in vitro and in vivo evaluation is needed to assess its efficacy for optimal transformation to clinical administration.

Supplementary Materials: The following are available online at https:/ www.mdpi.com/article/ 10.3390/pr9101814/s1, Figure S1: A ray-traced picture of the simulated system for 'DTQ-3CLpro' complex. Here, the simulation cell bound-ary is set to periodic. Figure S2: A ray-traced picture of the simulated system for 'DTQ-Nsp15' complex. Here, the simulation cell boundary is set to periodic.

Author Contributions: Conceptualization, funding acquisition, writing-review and editing, and supervision, S.M.D.R., T.H. and M.A.; Methodology, software, and writing-original draft preparation, A.M., Q.M.S.J. and A.S.A.; Validation, formal analysis, writing-review and editing, S.R.D., S.P.M., D.C.S. and R.U. All authors have read and agreed to the published version of the manuscript.

Funding: This research has been funded by Scientific Research Deanship at University of Ha'ilSaudi Arabia through project number RG-20 144.

Institutional Review Board Statement: Not applicable.

Informed Consent Statement: Not applicable.

Data Availability Statement: Not applicable.

Conflicts of Interest: The authors declare no conflict of interest.

\section{References}

1. Jakhmola, M.R.; Sehgal, N.; Dogra, N.; Saxena, S.; Pande, K.D. Deciphering underlying mechanism of Sars-CoV-2 infection in humans and revealing the therapeutic potential of bioactive constituents from Nigella sativa to combat COVID19: In-Silico study. J. Biomol. Struct. Dyn. 2020, 1-13, online ahead of print. [CrossRef] [PubMed]

2. WHO COVID-19, WHO 2020. Available online: https://www.who.int/health-topics/coronavirus\#tab=tab_1 (accessed on 13 December 2020).

3. McGonagle, D.; Sharif, K.; O'Regan, A.; Bridgewood, C. The Role of Cytokines including Interleukin-6 in COVID-19 induced Pneumonia and Macrophage Activation Syndrome-Like Disease. Autoimmun. Rev. 2020, 19, 102537. [CrossRef] 
4. Wu, C.; Chen, X.; Cai, Y.; Xia, J.; Zhou, X.; Xu, S.; Huang, H.; Zhang, L.; Zhou, X.; Du, C.; et al. Risk Factors Associated with Acute Respiratory Distress Syndrome and Death in Patients with Coronavirus Disease 2019 Pneumonia in Wuhan, China. JAMA Intern. Med. 2020, 180, 934-943. [CrossRef] [PubMed]

5. Cascella, M.; Rajnik, M.; Cuomo, A.; Dulebohn, S.C.; Di Napoli, R. Features, Evaluation, and Treatment of Coronavirus (COVID19). In StatPearls [Internet]; StatPearls Publisher: Treasure Island, FL, USA, 2021.

6. Song, Z.; Xu, Y.; Bao, L.; Zhang, L.; Yu, P.; Qu, Y.; Zhu, H.; Zhao, W.; Han, Y.; Qin, C. From SARS to MERS, Thrusting Coronaviruses into the Spotlight. Viruses 2019, 11, 59. [CrossRef] [PubMed]

7. Dhama, K.; Khan, S.; Tiwari, R.; Sircar, S.; Bhat, S.; Malik, Y.S.; Singh, K.P.; Chaicumpa, W.; Bonilla-Aldana, D.K.; RodriguezMorales, A.J. Coronavirus Disease 2019-COVID-19. Clin. Microbiol. Rev. 2020, 33, e00028-20. [CrossRef]

8. Guo, Y.R.; Cao, Q.D.; Hong, Z.S.; Tan, Y.Y.; Chen, S.D.; Jin, H.J.; Tan, K.S.; Wang, D.Y.; Yan, Y. The origin, transmission and clinical therapies on coronavirus disease 2019 (COVID-19) outbreak-An update on the status. Mil. Med. Res. 2020, 7, 11. [CrossRef]

9. Boopathi, S.; Poma, A.B.; Kolandaivel, P. Novel 2019 coronavirus structure, mechanism of action, antiviral drug promises and rule out against its treatment. J. Biomol. Struct. Dyn. 2020, 1-10, online ahead of print. [CrossRef]

10. Mirza, M.U.; Froeyen, M. Structural elucidation of SARS-CoV-2 vital proteins: Computational methods reveal potential drug candidates against main protease, Nsp12 polymerase and Nsp13 helicase. J. Pharm. Anal. 2020, 10, 320-328. [CrossRef]

11. Angeletti, S.; Benvenuto, D.; Bianchi, M.; Giovanetti, M.; Pascarella, S.; Ciccozzi, M. COVID-2019: The role of the nsp2 and nsp3 in its pathogenesis. J. Med. Virol. 2020, 92, 584-588. [CrossRef]

12. Chan, J.F.; Kok, K.H.; Zhu, Z.; Chu, H.; To, K.K.; Yuan, S.; Yuen, K.Y. Genomic characterization of the 2019 novel humanpathogenic coronavirus isolated from a patient with atypical pneumonia after visiting Wuhan. Emerg. Microbes Infect. 2020, 9 , 221-236. [CrossRef]

13. Lin, L.T.; Hsu, W.C.; Lin, C.C. Antiviral natural products and herbal medicines. J. Tradit. Complementary Med. 2014, 4, 24-35. [CrossRef] [PubMed]

14. Koshak, D.A.E.; Koshak, P.E.A. Nigella sativa L. as a potential phytotherapy for coronavirus disease 2019: A mini review of in silico studies. Curr. Ther. Res. Clin. Exp. 2020, 93, 100602. [CrossRef]

15. Ahmad, A.; Husain, A.; Mujeeb, M.; Khan, S.A.; Najmi, A.K.; Siddique, N.A.; Damanhouri, Z.A.; Anwar, F. A review on therapeutic potential of Nigella sativa: A miracle herb. Asian Pac. J. Trop. Biomed. 2013, 3, 337-352. [CrossRef]

16. Molla, S.; Azad, M.A.K.; Al Hasib, M.A.A.; Hossain, M.M.; Ahammed, S.; Rana, S.; Islam, M.T. A review on antiviral effects of Nigella sativa L. Pharmacol. Online 2019, 2, 47-53.

17. Barakat, A.B.; Shoman, S.A.; Dina, N.; Alfarouk, O.R. Antiviral activity and mode of action of Dianthus caryophyllus L. and Lupinus termes L. seed extracts against in vitro herpes simplex and hepatitis A viruses infection. J. Microbiol. Antimicrob. 2010, 2, $23-29$.

18. Oyero, O.G.; Toyama, M.; Mitsuhiro, N.; Onifade, A.A.; Hidaka, A.; Okamoto, M.; Baba, M. Selective inhibition of hepatitis c virus replication by alpha-zam, a Nigella sativa seed formulation. Afr. J. Tradit. Complementary Altern. Med. 2016, 13, 144-148. [CrossRef]

19. Dorra, N.H.; El-Barrawy, M.A.; Sallam, S.M.; Mahmoud, R.S. Evaluation of Antiviral and Antioxidant Activity of Selected Herbal Extracts. J. High Inst. Public Health 2019, 49, 36-40. [CrossRef]

20. Toma, C.C.; Simu, G.M.; Hanganu, D.A.; Olah, N.; Vata, F.M.; Hammami, C.; Hammami, M. Chemical composition of the Tunisian Nigella sativa. Note I. Profile on essential oil. Farmacia 2010, 58, 458-464.

21. Sahak, M.K.; Kabir, N.; Abbas, G.; Draman, S.; Hashim, N.H.; Hasan Adli, D.S. The role of Nigella sativa and its active constituents in learning and memory. Evid.-Based Complementary Altern. Med. 2016, 2016, 6075679. [CrossRef]

22. Ghahramanloo, K.H.; Kamalidehghan, B.; Javar, H.A.; Widodo, R.T.; Majidzadeh, K.; Noordin, M.I. Comparative analysis of essential oil composition of Iranian and Indian Nigella sativa L. extracted using supercritical fluid extraction and solvent extraction. Drug Des. Dev. Ther. 2017, 11, 2221. [CrossRef] [PubMed]

23. Haseena, S.; Aithal, M.; Das, K.K.; Saheb, S.H. Phytochemical analysis of Nigella sativa and its effect on reproductive system. J. Pharm. Sci. Res. 2015, 7, 514.

24. Astani, A.; Reichling, J.; Schnitzler, P. Screening for antiviral activities of isolated compounds from essential oils. Evid.-Based Complementary Altern. Med. 2011, 2011, 253643. [CrossRef]

25. Yang, Z.; Wu, N.; Zu, Y.; Fu, Y. Comparative anti-infectious bronchitis virus (IBV) activity of (-)-pinene: Effect on nucleocapsid (N) protein. Molecules 2011, 16, 1044-1054. [CrossRef] [PubMed]

26. Wang, L.; Wang, D.; Wu, X.; Xu, R.; Li, Y. Antiviral mechanism of carvacrol on HSV-2 infectivity through inhibition of RIP3mediated programmed cell necrosis pathway and ubiquitin-proteasome system in BSC-1 cells. BMC Infect. Dis. 2020, $20,832$. [CrossRef]

27. Lasarte-Cia, A.; Lozano, T.; Pérez-González, M.; Gorraiz, M.; Iribarren, K.; Hervás-Stubbs, S.; Sarobe, P.; Rabal, O.; CuadradoTejedor, M.; García-Osta, A.; et al. Immunomodulatory properties of carvone inhalation and its effects on contextual fear memory in mice. Front. Immunol. 2018, 9, 68. [CrossRef]

28. Sharifi-Rad, J.; Salehi, B.; Schnitzler, P.; Ayatollahi, S.A.; Kobarfard, F.; Fathi, M.; Eisazadeh, M.; Sharifi-Rad, M. Susceptibility of herpes simplex virus type 1 to monoterpenes thymol, carvacrol, p-cymene and essential oils of Sinapis arvensis L., Lallemantia royleana Benth. and Pulicaria vulgaris Gaertn. Cell. Mol. Biol. 2017, 63, 42-47. [CrossRef]

29. Ryabchenko, B.; Tulupova, E.; Schmidt, E.; Wlcek, K.; Buchbauer, G.; Jirovetz, L. Investigation of anticancer and antiviral properties of selected aroma samples. Nat. Prod. Commun. 2008, 3, 1085-1087. [CrossRef] 
30. Gavanji, S.; Sayedipour, S.S.; Larki, B.; Bakhtari, A. Antiviral activity of some plant oils against herpes simplex virus type 1 in Vero cell culture. J. Acute Med. 2015, 5, 62-68. [CrossRef]

31. Haddad, J.G.; Picard, M.; Bénard, S.; Desvignes, C.; Desprès, P.; Diotel, N.; El Kalamouni, C. Ayapana triplinervis essential oil and its main component thymohydroquinone dimethyl ether inhibit Zika virus at doses devoid of toxicity in zebrafish. Molecules 2019, 24, 3447. [CrossRef] [PubMed]

32. Lai, W.L.; Chuang, H.S.; Lee, M.H.; Wei, C.L.; Lin, C.F.; Tsai, Y.C. Inhibition of herpes simplex virus type 1 by thymol-related monoterpenoids. Planta Med. 2012, 78, 1636-1638. [CrossRef]

33. Badary, O.A.; Hamza, M.S.; Tikamdas, R. Thymoquinone: A Promising Natural Compound with Potential Benefits for COVID-19 Prevention and Cure. Drug Des. Dev. Ther. 2021, 15, 1819. [CrossRef]

34. Chakravarty, N. Inhibition of histamine release from mast cells by nigellone. Ann Allergy Asthma Immunol. 1993, 70, 237-242.

35. El-Dakhakhny, M.; Madi, N.J.; Lembert, N.; Ammon, H.P. Nigella sativa oil, nigellone and derived thymoquinone inhibit synthesis of 5-lipoxygenase products in polymorphonuclear leukocytes from rats. J. Ethnopharmacol. 2002, 81, 161-164. [CrossRef]

36. Faiza, M.; Abdullah, T.; Wang, P. Dithymoquinone as a novel inhibitor for 3-carboxy-4-methyl-5-propyl-2-furanpropanoic acid (CMPF) to prevent renal failure. arXiv 2017, arXiv:1709.03813.

37. Jin, Z.; Du, X.; Xu, Y.; Deng, Y.; Liu, M.; Zhao, Y.; Zhang, B.; Li, X.; Zhang, L.; Peng, C.; et al. Structure of Mpro from SARS-CoV-2 and discovery of its inhibitors. Nature 2020, 582, 289-293. [CrossRef]

38. Kim, Y.; Jedrzejczak, R.; Maltseva, N.I.; Wilamowski, M.; Endres, M.; Godzik, A.; Michalska, K.; Joachimiak, A. Crystal structure of Nsp15 endoribonuclease NendoU from SARS-CoV-2. Protein Sci. 2020, 29, 1596-1605. [CrossRef] [PubMed]

39. www.openmolecules.org. Available online: http://www.openmolecules.org/datawarrior/download.html (accessed on 7 December 2020).

40. Lipinski, C.A.; Lombardo, F.; Dominy, B.W.; Feeney, P.J. Experimental and computational approaches to estimate solubility and permeability in drug discovery and development settings. Adv. Drug Deliv. Rev. 2001, 46, 3-26. [CrossRef]

41. Rizvi, S.M.D.; Shakil, S.; Haneef, M. A simple click by click protocol to perform docking: AutoDock 4.2 made easy for nonbioinformaticians. EXCLI J. 2013, 12, 831-857. [PubMed]

42. Laskowski, R.A.; Swindells, M.B. LigPlot+: Multiple ligand-protein interaction diagrams for drug discovery. J. Chem. Inf. Model. 2011, 51, 2778-2786. [CrossRef]

43. Krieger, E.; Vriend, G. YASARA View-Molecular graphics for all devices—From smartphones to workstations. Bioinformatics 2014, 30, 2981-2982. [CrossRef]

44. Krieger, E.; Dunbrack, R.L., Jr.; Hooft, R.W.; Krieger, B. Assignment of protonation states in proteins and ligands: Combining pKa prediction with hydrogen bonding network optimization. Methods Mol. Biol. 2012, 819, 405-421.

45. Maier, J.A.; Martinez, C.; Kasavajhala, K.; Wickstrom, L.; Hauser, K.E.; Simmerling, C. ff14SB: Improving the Accuracy of Protein Side Chain and Backbone Parameters from ff99SB. J. Chem. Theory Comput. 2015, 11, 3696-3713. [CrossRef] [PubMed]

46. Jakalian, A.; Jack, D.B.; Bayly, C.I. Fast, efficient generation of high-quality atomic charges. AM1-BCC model: II. Parameterization and validation. J. Comput. Chem. 2002, 23, 1623-1641. [CrossRef] [PubMed]

47. Wang, J.; Wolf, R.M.; Caldwell, J.W.; Kollman, P.A.; Case, D.A. Development and testing of a general amber force field. J. Comput. Chem. 2004, 25, 1157-1174. [CrossRef] [PubMed]

48. Krieger, E.; Vriend, G. New ways to boost molecular dynamics simulations. J. Comput. Chem. 2015, 36, 996-1007. [CrossRef]

49. Berendsen, H.J.C.; Postma, J.P.M.; van Gunsteren, W.F.; DiNola, A.; Haak, J.R. Molecular dynamics with coupling to an external bath. J. Chem. Phys. 1984, 81, 3684-3690. [CrossRef]

50. Hess, B.; Bekker, H.; Berendsen, H.J.C.; Fraaije, J.G.E.M. LINCS: A linear constraint solver for molecular simulations. J. Comput. Chem. 1997, 18, 1463-1472. [CrossRef]

51. Keretsu, S.; Bhujbal, S.P.; Cho, S.J. Rational approach toward COVID-19 main protease inhibitors via molecular docking, molecular dynamics simulation and free energy calculation. Sci. Rep. 2020, 10, 17716. [CrossRef]

52. Islam, R.; Parves, M.R.; Paul, A.S.; Uddin, N.; Rahman, S.; Mamun, A.A.; Hossain, N.; Ali, A.; Halim, M.A. A molecular modeling approach to identify effective antiviral phytochemicals against the main protease of SARS-CoV-2. J. Biomol. Struct. Dyn. 2020, $1-12$, online ahead of print. [CrossRef]

53. Lobo-Galo, N.; Terrazas-López, M.; Martínez-Martínez, A.; Díaz-Sánchez, Á.G. FDA-approved thiol-reacting drugs that potentially bind into the SARS-CoV-2 main protease, essential for viral replication. J. Biomol. Struct. Dyn. 2020, 1-9, online ahead of print. [CrossRef]

54. Deng, X.; Hackbart, M.; Mettelman, R.C.; O’Brien, A.; Mielech, A.M.; Yi, G.; Kao, C.C.; Baker, S.C. Coronavirus nonstructural protein 15 mediates evasion of dsRNA sensors and limits apoptosis in macrophages. Proc. Natl. Acad. Sci. USA 2017, 114, E4251-E4260. [CrossRef] [PubMed]

55. Sinha, S.K.; Shakya, A.; Prasad, S.K.; Singh, S.; Gurav, N.S.; Prasad, R.S.; Gurav, S.S. An in-silico evaluation of different Saikosaponins for their potency against SARS-CoV-2 using NSP15 and fusion spike glycoprotein as targets. J. Biomol. Struct. Dyn. 2020, 1-12, online ahead of print. [CrossRef] [PubMed] 